\title{
O Mar do Sul da China: seu valor estratégico e a geoestratégia chinesa
}

\author{
El Mar del Sur de China: su valor estratégico y la \\ geoestrategia china
}

\section{The South China Sea: its strategic value and the Chinese geostrategy}

\author{
iD) Raphael Padula \\ Universidade Federal do Rio de Janeiro, Rio de Janeiro, Rio de Janeiro, Brasil \\ padula.raphael@gmail.com \\ (iD) Felipe Gusmão Carioni Fernandes \\ Universidade Federal do Rio de Janeiro, Rio de Janeiro, Rio de Janeiro, Brasil \\ felipecarioni@hotmail.com
}

Resumo: O objeto deste artigo é o Mar do Sul da China, tendo como argumento central que este se constitui em um espaço estratégico para a consecução dos interesses da China em termos políticos, econômicos e militares. O artigo averigua que esse espaço é estratégico para a China por conta de seus recursos naturais e de sua posição estratégica para a segurança e a projeção econômica e militar chinesa. Ainda, o texto aborda como se dá a expansão chinesa, sua geoestratégia para esse espaço. O artigo se apoia em uma revisão bibliográfica dos teóricos da geopolítica clássica e da conjuntura geopolítica atual, além de autores especialistas sobre o tema - como Robert Kaplan, Ian Storey, Clive Schofield e Yoji Koda - e da análise de documentos como a Convenção sobre o Direito do Mar, a Lei de Águas Territoriais, o Código de Conduta no Mar do Sul da China.

Palavras-chave: China. Mar do Sul da China. Sudeste Asiático. Geopolítica. Estudos Estratégicos. 
Resumen: El objeto de este artículo es el Mar del Sur de China, teniendo como el argumento central que éste se constituye en un espacio estratégico para la consecución de los intereses de China en términos políticos, económicos y militares. El artículo averigua que ese espacio es estratégico para China por cuenta de sus recursos naturales y de su posición estratégica para la seguridad y la proyección económica y militar china. Además, el texto aborda cómo se da la expansión china, su geoestrategia para ese espacio. El artículo se apoya en una revisión bibliográfica de los teóricos de la geopolítica clásica y de la coyuntura geopolítica actual, además de autores especialistas sobre el tema - como Robert Kaplan, Ian Storey, Clive Schofield y Yoji Koda- y del análisis de documentos como la Convención sobre el Derecho del Mar, la Ley de Aguas Territoriales, el Código de Conducta en el Mar del Sur de China.

Palabras clave: China. Mar del Sur de China. Sudeste Asiático. Geopolítica. Estudios estratégicos.

Abstract: The object of this article is the South China Sea with the central argument that it constitutes a strategic space for the attainment of China's political, economic and military interests. The article finds that this space is strategic for China because of its natural resources and its strategic position for Chinese security and economic and military projection. Still, the text addresses how the Chinese expansion happens, its geostrategy for this space. The article is based on a bibliographical review of classical geopolitical theorists and on the current geopolitical conjuncture, as well as on expert authors on the subject - such as Robert Kaplan, Ian Storey, Clive Schofield and Yoji Koda - and the analysis of documents such as the Convention on the Law of the Sea, Territorial Water Law, Code of Conduct in the South China Sea.

Keywords: China. South China Sea. Southeast Asia. Geopolitics. Strategic Studies.

Data de recebimento do artigo: 09/02/2019

Data de aprovação do artigo: 26/04/2019 


\section{Introdução}

O objeto deste artigo é o Mar do Sul da China (MSC, daqui para frente), tendo como argumento central de que ele se constitui em um espaço estratégico para a consecução dos interesses da China em termos políticos, econômicos e militares mesmo dentro do prisma de montagem de uma "sociedade harmoniosa e moderadamente próspera"1. Para isso, o artigo averigua quais são os elementos que tornam esse espaço desejável ou estratégico vide os interesses chineses, observando tanto seus recursos naturais quanto sua posição estratégica para segurança e projeção econômica e militar chinesa. Nesse sentido, a presença de rivais, ou a possibilidade destes auferirem vantagens atuando na região, é um elemento importante. Ainda, o texto aborda como se dá a expansão chinesa e, consequentemente, sua geoestratégia, bem como, ao mesmo tempo, sua busca por amenizar possíveis vulnerabilidades decorrentes da presença de disputas regionais e projeção de potências externas nesse espaço.

O artigo está estruturado em três seções, além dessa introdução e da seção final de conclusões. A primeira seção aborda aspectos teóricos da geopolítica clássica e da conjuntura geopolítica atual, com destaque para a China. A seção seguinte aborda os aspectos geográficos do MSC que revelam seu valor econômico e estratégico, em termos de espaço (no sentido dos recursos presentes nessa área) e posição geográfica relativa, sendo reveladores do interesse chinês e dos conflitos presentes e latentes. A última seção trata da geoestratégia do Estado chinês para o MSC e alternativas de comunicações. A abordagem teórica é de viés realista e geopolítico, partindo dos fatores geográficos para analisar suas implicações para os interesses e estratégias dos Estados. A metodologia adotada privilegia a revisão bibliográfica de autores especialistas sobre o tema como Robert Kaplan, Ian Storey, Clive

\footnotetext{
1 A construção de uma "sociedade harmoniosa e moderadamente próspera" se torna o objetivo de longo prazo do Partido Comunista Chinês (PCC) quando da ascensão de Hu Jintao como Presidente da República (2003-2013) e Wen Jiabao no cargo de Primeiro-Ministro (2003-2013). De acordo com a visão dos líderes do PCC, as primeiras duas décadas dos anos 2000 seriam um momento de "oportunidade estratégica" para a China avançar em seu desenvolvimento, porém sempre tendo como princípio para isso a "ascensão pacífica".
} 
O Mar do Sul da China: seu valor estratégico e a geoestratégia chinesa Raphael Padula • Felipe Gusmão Carioni Fernandes

Schofield e Yoji Koda. Além da consulta a documentos como a Convenção sobre o Direito do Mar (ONU, 1982), Declaração sobre o Mar do Sul da China (ASEAN, 1992), Lei sobre Águas Territoriais e Zonas Adjacentes (CHINA, 1992), Declaração sobre o Código de Conduta no Mar do Sul da China (ASEAN, 2002).

\section{Visão teórica}

Considerado um dos pioneiros da geopolítica clássica, o alemão Friedrich Ratzel (1897) apontou dois fatores geográficos fundamentais que condicionam a ação estratégica de um Estado que são: o seu espaço de domínio político e sua posição geográfica relativa. Quanto ao espaço (raum), engloba todos os recursos (conteúdo) presentes em um território, assim como suas condições de coesão nacional. No que diz respeito à situação geográfica (lage), importa a posição em relação a mares, continente, portos, planícies, elevações, rotas comerciais (terrestres e marítimas), polos de poder globais e vizinhança. Deve-se levar em conta ainda o conceito de espaço vital apresentado pelo autor, como o domínio territorial adequado a ser buscado pelo Estado, considerando a presença de recursos e o tamanho da população, para que ela possa viver e se desenvolver de forma adequada. Justifica-se assim a expansão territorial baseada em um argumento humanista e antimalthusiano (COSTA, 2005)², mas, ao mesmo tempo, prioriza-se a busca pela autossuficiência (ou autarquia) como forma de depender o mínimo possível das relações exteriores, internalizando a produção de bens essenciais para o funcionamento e desenvolvimento do país, tornando-o menos vulnerável economicamente, politicamente e militarmente, frente aos demais Estados. É importante notar que, ao olhar para a experiência expansionista de grandes potências,

\footnotetext{
2 O economista britânico Thomas Malthus desenvolveu uma visão pessimista ao observar o crescimento geométrico da população diante do crescimento aritmético da produção agrícola para sua subsistência. Para ele, o ajuste entre o tamanho da população e da produção para sua subsistência se daria na primeira, através da mortalidade, ou controlando a natalidade. Ratzel inverte esse raciocínio e, sob bases nacionais, justifica a expansão territorial.
} 
O Mar do Sul da China: seu valor estratégico e a geoestratégia chinesa Raphael Padula • Felipe Gusmão Carioni Fernandes

Ratzel identificou a possibilidade da utilização de meios econômicos, culturais e políticos, para o domínio de recursos e territórios, tanto no plano interno como no internacional ${ }^{3}$. Nesse sentido, comércio, investimentos e a construção de infraestrutura poderiam servir tanto à exploração econômica quanto ao domínio político de recursos e territórios.

O almirante estadunidense Alfred Mahan (1890), ao apresentar sua teoria do poder marítimo, destaca a importância do domínio dos mares e oceanos para a construção da supremacia global britânica no século XIX. Em particular, o autor considera que o controle de rotas e passagens estratégicas e seus pontos de apoio, que garantiriam a mobilidade das marinhas mercante e de guerra, seriam fundamentais para a expansão comercial segura (baseada na exportação manufatureira) e mesmo para a segurança do território. Já Halford Mackinder (1904), ao olhar para a expansão e interconexão territorial russa, apontou a relevância do poder terrestre devido ao advento tecnológico das grandes ferrovias transcontinentais, que permitiam tanto mobilidade interna quanto projeção de poder externa, para dominar territórios e recursos, e bem como promover sua segurança. Assim, com sua maior capacidade de mobilidade, deslocaria a importância das rotas comerciais marítimas.

Nicholas Spykman, holandês radicado nos Estados Unidos, colocou luz sobre a área do rimland ${ }^{4}$ da Eurásia, em contraposição ao heartland 5 de Mackinder. Ambos acreditavam que a Eurásia seria o continente basilar na disputa de poder global por razões materiais (concentração de terras emersas, população, recursos econômicos e militares). Mas Spykman (1944) aponta que as fímbrias marítimas da Eurasia, o rimland, seria a área estratégica na disputa de

\footnotetext{
3 Dentre as "Leis de crescimento espacial dos Estados" formuladas por Ratzel em 1895, uma delas aponta que o crescimento espacial dos Estados acompanha diversas expressões do seu desenvolvimento, como: produção e difusão de ideologia; produção física; atividade comercial; atividade missionária. Segundo Octavio Tosta, em Teorias Geopolíticas (Rio de Janeiro: Bibliex, 1984, p. 11), esta teria sido apelidada como "lei da penetração pacífica" por Everardo Backheuser.

4 Segundo Mello (1999, p. 120), o Rimland se localizaria entre o "anel desértico e montanhoso que circundava a planície siberiana e, por outro lado, com o semicírculo marítimo que contornava o continente eurasiano". Assim sendo, a área de contato entre o litoral da Eurásia e o cordão de mares marginais que a cercam, constituindo-se como a via expressa marítima do tráfego comercial e militar da Ilha Mundial, que conecta a África e o Oriente Médio ao Leste Asiático (KAPLAN, 2013, p. 104).

5 De acordo com Mackinder o Heartland seria o coração continental da Eurásia, a área basilar onde se existiria imensa riqueza natural e estratégica, de difícil acesso pelo mar e que, por sua posição geográfica central, possibilitaria ao Estado que a dominasse a expansão terrestre em todas as direções. Tal região ao longo de sua história foi controlada principalmente pelos russos (MELLO, 1999).
} 
poder no continente. Os Estados localizados nessa região, como a China, sofreriam um duplo problema de segurança, podendo ser atacados pela terra ou por mar. No entanto, teriam também uma dupla potencialidade de expansão (anfíbia), que os dariam maior possibilidade de conquistar a Eurásia, além de conter o poder terrestre do heartland. Assim, a China, localizada no rimland do continente basilar, seria um país continental e, ao mesmo, tempo com uma frente marítima de expansão, para a qual veremos a importância do MSC. Vale lembrar que Mackinder (apud MELLO, 1999) vislumbrou que a China e a Índia seriam os prováveis polos de poder no futuro, por situarem-se nessa área e por possuírem antigas civilizações, com grandes populações e grandes territórios.

Vale ressaltar que desde o ponto de vista da geopolítica clássica, os conflitos geopolíticos podem ser originados por razões econômicas, mas seu principal foco está nas motivações de segurança, ou seja, no equilíbrio de poder. Essa é uma importante diferença em relação à visão geopolítica marxista de David Harvey (2005), inspirada na teoria do imperialismo e na teoria da dependência, na qual a expansão capitalista, seguindo o interesse da burguesia capitalista, levaria a choques de interesses entre Estados por razões econômicas, como domínio de recursos e mercados.

Além das questões perenes relativas à geografia do MSC, que serão tratadas na próxima seção a partir da teoria já apresentada, é preciso também olhar para sua geopolítica conjuntural. Ambas vão influenciar a geoestratégia da China para a região, objeto da última seção.

Como nota Mello (2002), a geopolítica possui um caráter dinâmico. Isso se deve não só a mudanças na distribuição de poder, mas ao fato de avanços tecnológicos poderem alterar tanto a capacidade de mobilidade (para projeção de poder e defesa dos Estados, por terra, mar e ar, por exemplo) quanto o valor econômico e estratégico dos territórios (espaços e posições), devido à mudança na capacidade de explorar/utilizar seus recursos e/ou rotas. Nesse sentido, é importante notar a crescente valorização do mar (e dos fundos oceânicos) como fonte de recursos naturais a partir 
dos anos 1970. E é a partir desse período que se pode constatar uma crescente busca por parte dos Estados para dominar espaços marítimos, assim como o surgimento de negociações e instituições para regular as atividades e domínios marítimos (BROZOSKI, 2018). Dentro desse fenômeno, os espaços marítimos podem ser analisados não somente do ponto de vista do valor econômico e estratégico de sua posição em rotas comerciais ou de segurança, como em Mahan (1890), mas também em termos de presença de recursos naturais exploráveis (como espaço de domínio) visando uma menor dependência do abastecimento de bens essenciais a partir de outros Estados, no sentido de Ratzel (1897).

A geopolítica do século XXI é caracterizada por uma crescente competição pela concentração de poder e pelo controle e acesso facilitado a recursos naturais. Desde os anos 1970, quando romperam unilateralmente com o Sistema de Bretton Woods, os EUA iniciaram uma política expansiva para enquadrar rivais revelados e potenciais, vencer a Guerra Fria e, a partir da década de 1990, para manter a unipolaridade pós-Guerra Fria. Nos anos 2000, a Rússia, uma antiga potência, nacionaliza empresas estratégicas e retoma uma política externa assertiva com a chegada de Putin ao poder, especialmente no seu entorno geográfico rico em recursos energéticos (FIORI \& PADULA, 2015). Nessa conjuntura, o cientista político estadunidense Michael Klare (2008) destaca a ascensão da China e da Índia, que crescem economicamente a altas taxas, pois são países importadores de recursos naturais com significativas populações, buscando incorporá-las às cidades e mercados de trabalho e consumidor. Para ele, as pressões e novas configurações geopolíticas na competição pelo acesso e controle de recursos energéticos geradas pela ascensão desses países representariam um novo desafio, que chama de "Chindia Challenge". É no âmbito dessa pressão competitiva que se pode observar a busca por recursos e posições estratégicas, gerando conflitos, tanto nos continentes quanto nos fundos marinhos. São recursos críticos cujo domínio, possibilidade ou ausência de acesso geram implicações econômicas, mas também políticas e estratégicas, na autonomia, 
na segurança, na projeção externa e nos projetos políticos dos Estados (LE BILLON, 2005). A geógrafa brasileira Bertha Becker (2005) chega a apontar que os fundos marinhos seriam um dos "eldorados" da expansão do capitalismo no século XXI.

Do ângulo da geoestratégia da China, o Mar do Sul da China se destaca tanto pela sua posição quanto pelo seu conteúdo. Tanto pelo equilíbrio de poder regional, quanto por sua conexão com a disputa de poder global.

\section{A Geografia do Mar do Sul da China: posição e recursos naturais estratégicos}

\section{Posição geográfica}

Seguindo a aproximação teórica exposta na seção anterior, devemos esclarecer a relevância do Mar do Sul da China (MSC) em termos de espaço (recursos) e posição para o contexto geopolítico euro-asiático, que logo incita a ganância das unidades estatais, assim como para os interesses e acúmulo de poder do Estado chinês.

O MSC é uma área marítima de aproximadamente 3,8 milhões de km², localizado no Sudeste Asiático, onde interagem China, Taiwan, Malásia, Brunei, Indonésia, Singapura, Vietnã, Filipinas, Camboja e Tailândia, totalizando aproximadamente 2 bilhões de pessoas vivendo em uma das regiões que correntemente apresenta as maiores taxas de desenvolvimento do mundo. Constituindose em uma das zonas de tráfego marítimo mais movimentadas do planeta e, assim, uma rota marítima estratégica em termos de importância econômica para os países da região, no sentido destacado por Mahan. Segundo a The United Nations Conference on Trade and Development (UNCTAD), aproximadamente $80 \%$ do total global por volume e $70 \%$ do total global por valor do comércio mundial são transportados pelo mar. Desse montante, 60\% passa 
O Mar do Sul da China: seu valor estratégico e a geoestratégia chinesa Raphael Padula • Felipe Gusmão Carioni Fernandes

através da Ásia sendo que um terço necessariamente transita pelo MSC. Como dado ilustrativo, a porcentagem que o MSC representa para o comércio de Indonésia, Malásia, Coréia do Sul, Japão, Vietnã e Tailândia é respectivamente de $85 \%, 58 \%, 47 \%, 19 \%, 86 \%, 74 \%$ (CHINA POWER, 2017).

Sobre isso, Moraes (2015, p. 575) reforça nosso argumento ao colocar que "os terminais de contêineres dos portos de Singapura, Hong Kong, Shenzhen e Guangzhou estiveram entre os dez maiores do mundo em volume movimentado no período 2010-2011, respondendo por cerca de um terço do total global". Ainda, conforme destacado por Pereira (2004, p. 104):

As rotas marítimas que ligam o Nordeste Asiático e a zona Ocidental do Pacífico ao Oceano Índico e ao Médio Oriente atravessam o MSC; Mais de 40.000 navios, representando mais de metade da tonelagem total a nível mundial, circulam anualmente no MSC. (...) Cerca de 15\% do volume total do comércio mundial transita pelas Rotas Marítimas de Comunicação do Sudeste Asiático; Mais de $80 \%$ do petróleo com destino ao Japão, Coreia do Sul e Taiwan é transportado via MSC.

Para adentrar e sair do MSC deve-se passar por uma geografia semicerrada e recortada por chokepoints, tais como os Estreitos de Luzon, Taiwan no Norte e os gargalos de Malaca, Sunda e Lombok ao Sul, que se revelam como pontos de passagens estratégicos de rotas comerciais no sentido apresentado por Mahan. Conforme definição de estudo da agência estatal estadunidense Energy Information Administration (2011, p. 1, tradução nossa), "os Chokepoints são canais estreitos ao longo de rotas marítimas globais amplamente utilizadas, algumas tão estreitas que o tamanho da embarcação que pode navegar através delas pode sofrer restrições" ${ }^{\prime \prime}$ Essas passagens são críticas para a segurança energética de muitos Estados.

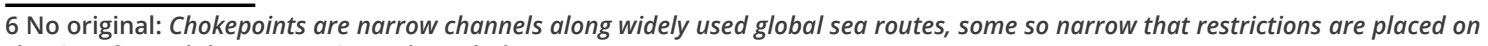
the size of vessel that can navigate through them. 
O Mar do Sul da China: seu valor estratégico e a geoestratégia chinesa Raphael Padula • Felipe Gusmão Carioni Fernandes

A passagem de maior importância entre as supracitadas é Malaca. Esse gargalo é central para o transporte de mercadorias e recursos estratégicos entre a região do Golfo Pérsico e do Pacífico, sendo fundamental para as economias de países como China, Japão, Coreia do Sul e Taiwan. A relevância do Estreito de Malaca no contexto regional e global foi apropriadamente resumida por Villar \& Hamilton (2017, p. 1-2, tradução nossa) da seguinte maneira7:

Quase um terço dos $61 \%$ da produção global de petróleo e outros líquidos que se deslocaram pelas rotas marítimas em 2015 transitaram pelo Estreito de Malaca, o segundo maior ponto de estrangulamento do comércio de petróleo no mundo depois do Estreito de Ormuz [...] O Estreito de Malaca, [...] É a rota marítima mais curta entre os fornecedores do Golfo Pérsico e os principais mercados asiáticos. O Estreito de Malaca é o principal ponto de estrangulamento na Ásia e, nos últimos anos, entre $85 \%$ e $90 \%$ do fluxo total anual de petróleo que transitou através deste ponto de estrangulamento foi de petróleo bruto [...] Em seu ponto mais fechado no Canal Phillips dentro do Estreito de Singapura, o Estreito de Malaca tem apenas 1,7 milhas de largura, criando um gargalo natural com potencial para colisões, encalhamentos ou vazamentos de óleo. De acordo com o Centro de Denúncia de Pirataria da Autoridade Marítima Internacional, a pirataria, incluindo tentativa de roubo e sequestro, é uma ameaça aos navios-tanques no Estreito de Malaca. Se o Estreito de Malaca fosse bloqueado, quase metade da frota de navios do mundo seria obrigada a se redirecionar ao redor do arquipélago indonésio, e seguir através do Estreito de Lombok ou do Estreito de Sunda. O reencaminhamento amarraria a capacidade de transporte global, aumentando os custos de envio e potencialmente afetando os preços da energia.

\footnotetext{
7 No original: Nearly one-third of the $61 \%$ of total global petroleum and other liquids production that moved on maritime routes in 2015 transited the Strait of Malacca, the second-largest oil trade chokepoint in the world after the Strait of Hormuz (..) The Strait of Malacca, (.) It is the shortest sea route between Persian Gulf suppliers and key Asian markets. The Strait of Malacca is the primary chokepoint in Asia, and in recent years, between $85 \%$ and $90 \%$ of annual total petroleum flows through this chokepoint were crude oil (.-) At its narrowest point in the Phillips Channel of the Singapore Strait, the Strait of Malacca is only about 1.7 miles wide, creating a natural bottleneck with the potential for collisions, grounding, or oil spills. According to the International Maritime Bureau's Piracy Reporting Centre, piracy, including attempted theft and hijackings, is a threat to tankers in the Strait of Malacca. If the Strait of Malacca were blocked, nearly half of the world's shipping fleet would be required to reroute around the Indonesian archipelago, such as through the Lombok Strait or through the Sunda Strait. Rerouting would tie up global shipping capacity, add to shipping costs, and potentially affect energy prices.
} 
Estima-se que, em caso de bloqueio desse passo, os custos de frete para redirecionar o tráfego para o Estreito de Sunda, no período de uma semana, devem chegar em 64.5 milhões de dólares. Enquanto que o redirecionamento para o Estreito de Lombok ficaria em 119 milhões. Por fim, caso os três estreitos estivessem bloqueados, os navios deveriam ir em direção a costa sul da Austrália acarretando em cerca de 2.8 bilhões de dólares ao mês. (CHINA POWER, 2017).

No que interessa à China, especificamente, é necessário realçar que o perímetro de segurança do país no Leste Asiático compreende a área que vai desde a península coreana até o Estreito de Malaca. Dentro dessa macrorregião existem três tabuleiros geopolíticos estratégicos à defesa do país. Do Norte para o Sul, são eles: o Mar Amarelo, o Mar do Leste da China e o próprio Mar do Sul da China. Aqui nos cabe analisar apenas este último espaço.

A China é extremamente dependente do comércio marítimo e de sua conexão com o MSC. Segundo a base de dados China Power Project (2017), 60\% do valor total do comércio chinês viaja pelo mar. E 64\% transitaram através do MSC. Esse quadro de dependência se agrava quando observados os trânsitos de recursos estratégicos. Storey \& Schofield (2009) colocam que, em 2006, os chineses importavam $43 \%$ de suas necessidades energéticas e previam que, em 2020, essa taxa deveria chegar em 60\%. Porém, o BP Statistical Review 2018 auferiu que a dependência chinesa das importações de energia já alcançou 68\% em 2017, superando as previsões desses autores. Somado a isso, 90\% dessas importações transitam através de estreitos marítimos perigosos (HOWELL, 2009). Nesse cenário, o gargalo de Malaca possui maior importância devido à sua proximidade com a China e por concentrar o comércio do país em um único ponto, sendo fundamental para garantir a mobilidade das marinhas mercante e de guerra da China por essa rota, considerando a visão de Mahan. Logo, o fechamento desse gargalo por uma potência rival, sob o argumento de garantir a segurança marítima contra a pirataria ${ }^{8}$, é uma possibilidade não descartada

8 Casos de sequestro de embarcações nas águas próximas ao Estreito de Malaca são um fato estabelecido e problemático para os Estados da região. Em 2014 registraram-se 15 casos e até julho de 2015 já haviam ocorrido nove. 
O Mar do Sul da China: seu valor estratégico e a geoestratégia chinesa Raphael Padula • Felipe Gusmão Carioni Fernandes

pelo Partido Comunista Chinês (PCC), uma vez que significaria um duro golpe na economia e na capacidade de mobilização militar do país. Dessa forma, Malaca representa uma permanente vulnerabilidade geopolítica no quadro da segurança chinesa.

Também, observa-se que o MSC é um espaço essencial como rota marítima para que a China alcance o Oceano Índico. O Mar do Sul pode inclusive ser considerado uma região tributária ao Índico, já que os dois estão conectados pela passagem de Malaca. A partir da perspectiva chinesa, o MSC é a porta de entrada para o Índico e para além dele o subcontinente indiano, África, Oriente Médio e Europa. Todas são regiões estratégicas aos interesses da China. Dentro do MSC, Malaca segura a chave para o Índico e se torna um ponto focal para a expansão chinesa em direção ao Ocidente.

Além disso, é preciso ressaltar que toda a extensão do litoral do país é cercada por um conjunto de Estados-arquipélagos, o que Kaplan (2013) convencionou chamar de a "Primeira Cadeia de Ilhas"9. Isso transforma os três mares da China (Amarelo, do Leste e do Sul) em geografias semicerradas, constrangendo tanto geográfica quanto politicamente a expansão chinesa em direção ao Oceano Pacífico. Para contornar tal restrição, a reincorporação de Taiwan ao âmago da RPC é fundamental, uma vez que furaria a barreira de ilhas. Contudo, devido à aliança entre Taipei e Washington, Pequim tem assumido uma postura de cautela e optado por uma política de longo prazo nesse quesito.

Sendo assim, percebe-se que o MSC e seus estreitos representam um ativo de importância estratégica para a mobilidade comercial e militar, assim como para o desenvolvimento econômico e social de uma grande faixa do continente Euro-asiático, especificamente do Nordeste e Sudeste da Ásia. Logo, qualquer alteração na possibilidade de acesso e de livre navegação através dessa área pode afetar negativamente Estados como Japão, Coreia do Sul, Taiwan e China, o que, consequentemente, implicaria não só em grande prejuízo a economia global como também na alteração do

9 A Primeira Cadeia de Ilhas compreende: a Coreia do Sul; o Japão; as Ilhas Ryukyu onde está localizada a base militar estadunidense de Okinawa; Taiwan; Filipinas; Malásia; e Indonésia. Assim, representa uma coerção geográfica que se torna também política e militar na medida em que tais países se aproximam da órbita de poder norte-americano. 
equilíbrio de poder nessas regiões. No que tange a China, o MSC possibilita a liberação das potencialidades marítimas chinesas, ou seja, para as possibilidades de expansão em dupla direção (terrestre e marítima) de um Estado anfíbio do rimland da Eurásia, para usar os termos de Spykman. Primeiro na direção do Oceano Índico, onde se concentram importantes rotas e parceiros comerciais e depois para o "Pacífico Aberto", onde correntemente estão sendo descobertas reservas minerais nos subsolos marinhos (SERRANO, 2017). Contudo, diante da expansão marítima, não podem ser relativizados os papéis desempenhados por Singapura, no que concerne sua centralidade diante do Estreito de Malaca, e Taiwan, referindo-se à penetração através da Primeira Cadeia de Ilhas.

\section{Espaço e recursos naturais}

O século XXI é caracterizado por um panorama de crescente demanda por recursos naturais (notadamente os energéticos), no qual ganham relevo as necessidades de China e Índia, o que Klare (2008) chamou de "Chindia challenge". Ao mesmo tempo, a dinâmica tecnológica impactou na geopolítica: os avanços no campo da prospecção profunda têm indicado que os mares, para além de seus valores econômicos e estratégicos tradicionais (vias de comércio e segurança nacional) apontados por Mahan (1890), ganharão cada vez mais importância como áreas produtoras de insumos para o avanço do poder industrial-militar e do poder estatal em geral, tais como petróleo, gás natural e minérios. Isso coloca os mares como espaços de domínio de recursos dos Estados e que podem ser alvo de sua expansão por contribuir para sua menor dependência externa ou na busca por seu "espaço vital", no sentido colocado por Ratzel. Logo, podendo ser encarados como uma das novas fronteiras de disputa interestatal (BECKER, 2005; KLARE, 2008; BROZOSKI, 2018). Não à toa, nos últimos anos, tem se registrado uma corrida pela demarcação de Zonas Econômicas Exclusivas (ZEE), assim como pedidos de extensão de plataformas continentais. O arcabouço jurídico da Convenção das Nações 
O Mar do Sul da China: seu valor estratégico e a geoestratégia chinesa Raphael Padula • Felipe Gusmão Carioni Fernandes

Unidas sobre os Direitos do Mar (UNCLOS, 1982), porém, oferece poucos instrumentos para a solução de controvérsias entre dois Estados que discordam quanto às delimitações ${ }^{10}$ de suas fronteiras marítimas. Fazendo com que a resolução de tais desacordos se mantenha ainda no campo da política interestatal. Esse problema toma maiores proporções quando ocorre em regiões mediterrâneas pululadas por grande número de Estados como é o caso do MSC.

Portanto, no que concerne aos recursos e elementos presentes no MSC, esta área é pontilhada por centenas de ilhas, recifes e rochedos podendo ser sublinhados os arquipélagos das Paracels, Spratlys e o recife de Scarborough, pois são áreas de disputa territorial entre os Estados da região. O domínio dessas formações expandiria a jurisdição dos países sobre áreas oceânicas e, consequentemente, sobre os recursos em suas proximidades.

O arquipélago de Paracel é constituído por um conjunto de aproximadamente 130 ilhas e recifes que totalizam uma área emersa de $7,75 \mathrm{~km}^{2}$, espalhados ao longo de $15 \mathrm{mil} \mathrm{km}^{2}$. Atualmente, as ilhas estão sob o controle e ocupação chinesa, apesar dos protestos de Taiwan e Vietnã que reclamam para si a soberania do arquipélago. A região é cercada por zonas pesqueiras e indícios de petróleo no subsolo marítimo que já foram encontrados pela companhia estatal China National Petroleum Company (CNPC) (LI, 2014).

Similarmente, o arquipélago das Spratlys é formado por aproximadamente 190 acidentes geográficos entre eles ilhas, recifes, atóis e rochedos. Com uma área emersa de pouco menos de 4 $\mathrm{km}^{2}$ que se espalham por mais de 450 mil km² ao longo do oceano. O potencial econômico reside nas áreas de pesca e reservas de óleo e gás inexploradas. Quanto às reservas, a primeira vez que foi encontrado gás natural na região foi em 1976 pelo governo filipino, porém, até hoje, existe grande debate acerca do tamanho

\footnotetext{
10 A principal corte de justiça internacional para julgar controvérsias marítimas é o Tribunal Internacional da Lei do Mar. Estabelecido em 1982 junto da UNCLOS o tribunal visa solucionar litígios quanto à interpretação das leis da Convenção, além de funcionar como órgão de consulta jurídica para os Estados. Contudo, dos 26 casos já julgados pela Corte apenas dois diziam respeito a delimitações de fronteiras marítimas, o que indica que ainda existe um baixo grau de jurisprudência produzida nesse âmbito.
} 
O Mar do Sul da China: seu valor estratégico e a geoestratégia chinesa Raphael Padula • Felipe Gusmão Carioni Fernandes

delas. Em relatório de 2013, a agência estadunidense EIA estima que não existam reservas provadas ou prováveis de óleo e gás na região das Spratlys. A US Geological Survey aufere que as reservas são desconhecidas, mas seriam da ordem de 0,8 até 5,4 bilhões de barris de óleo e de 7,6 até 55,1 trilhões de pés cúbicos de gás natural. Estudos de 2012, da China National Offshore Oil Corporation (CNOOC), observaram que o Mar do Sul da China pode ter reservas ainda não descobertas de até 125 bilhões de barris de petróleo e 500 trilhões de metros cúbicos de gás natural. É difícil ter estimativas mais confiáveis, pois a conjuntura de contestação política quanto à soberania das ilhas e das águas que as cercam impedem que trabalhos mais aprofundados sejam feitos. Correntemente, o controle das Spratlys é dividido e disputado por China, Taiwan, Vietnã, Filipinas, Malásia e Brunei, sendo que os cinco primeiros possuem instalações militares na área.

Por último, o recife de Scarborough é constituído por um conjunto de recifes, bancos de areia e rochas que se estendem por um perímetro de $49 \mathrm{~km}$ que, de acordo com os critérios postos pela Convenção das Nações Unidas sobre os Direitos do Mar (UNCLOS) e pelo Tribunal Internacional de Haia, está dentro da Zona Econômica Exclusiva (ZEE) das Filipinas. Ainda assim, a China contesta a soberania do recife, inclusive impedindo o acesso e exploração econômica da área. Em termos de recursos, o recife oferece não mais do que pescado e guano, e não há dados sobre possíveis riquezas advindas do subsolo marinho. Porém, a maior importância do recife de Scarborough é sua posição estratégica quando relacionada com os demais arquipélagos aqui já citados.

A partir do domínio dessas três áreas e do emprego de estratégias anti-access and area denial (A2/AD) ${ }^{11}$, é possível formar uma área de exclusão em uma região central do MSC (Triangulo Estratégico do MSC). Tal capacidade é estratégica uma vez que garante soberania militar sobre a região impedindo a entrada de forças militares indesejadas neste espaço. Logo, facilita-se o con-

\footnotetext{
11 “Em situações de guerra assimétrica, ou seja, nas quais há uma diferença considerável de força militar entre os adversários, costuma-se apelar para as chamadas estratégias antiacesso e de negação de entrada (anti-access/ area denial), nas quais o contendor mais fraco procura impedir ou dificultar para o inimigo o livre uso de determinadas áreas ou meios para atacar. São exemplos: minas terrestres, mísseis e minas antinavios, armas cibernéticas, antissatélites e emissoras de pulsos magnéticos" (KAPLAN, 2013, p. 220).
} 
trole político sobre os eventuais recursos e, assim, asseguram-se vantagens econômicas.

Como dito anteriormente, o Estado chinês depende em grande medida de seu comércio marítimo. Levando em consideração sua fraca dotação geológica para a extração de petróleo e gás natural, o país se torna refém da importação de recursos energéticos (HOWELL, 2009). Ao ponto que hoje a RPC figura entre os três maiores importadores de energia do mundo, além de ser o segundo maior consumidor. A origem desses recursos em sua maior parte é o Oriente Médio e a África, o que significa que para os petroleiros chegarem à costa chinesa devem, necessariamente, passar por Malaca e pelo MSC (EIA, 2014). Em 2016, 80\% das importações de petróleo da China transitaram através do Mar do Sul (CHINA POWER, 2017). Por isso, obter o controle sobre o Triangulo Estratégico asseguraria soberania sobre os recursos presentes no subsolo marinho. Amenizando a dependência chinesa do instável trânsito energético de longa distância.

Ademais, a grande diversidade de vida marinha do MSC é responsável por garantir, em boa parte, a segurança alimentar das populações do Sudeste Asiático, além de representarem valiosa fonte de receita para os atores regionais. Segundo um estudo de 2015, realizado por Sumaila \& Cheung, o MSC é lar de aproximadamente 3.365 espécies de peixes, sendo uma das cinco maiores zonas produtoras de pescado do planeta. É estimado que o volume de pesca bata na casa das 10 milhões de toneladas, o que corresponderia a $12 \%$ do volume mundial de pescados em um ano. Esse volume se traduziria em valores de 21.8 bilhões de dólares, dos quais a China deteria $45 \%$ do montante, correspondendo a 10,5\% de seu PIB do setor de agricultura.

Os produtos da pesca também têm grande valor para prover receitas de exportação para os países do Sudeste Asiático. Nesse quesito, a China detém 44\% do total de exportações da região, algo em torno de 16.9 bilhões de dólares (SUMAILA \& CHEUNG, 2015, p. 14). Portanto, os recursos vivos presentes no MSC, além de contribuírem para a segurança alimentícia de países que historicamente 
sofreram com a fome, também fornecem importantes receitas econômicas para que esses Estados continuem a se desenvolver.

Em conclusão, o MSC oferece recursos inestimáveis à amenização da dependência de abastecimento externo e das vulnerabilidades geopolíticas chinesas, no sentido ratzeliano. Aproveitando sua possibilidade de expansão marítima a partir do rimland, como visto, o domínio das ilhas do MSC garantiria ao país um espaço de soberania marítima ampliada que produziria efeitos positivos nos campos político e econômico. Devido, principalmente, à incorporação de reservas de recursos energéticos e alimentícios (provados ou potenciais) a poucos quilômetros da costa chinesa, diminuindo, assim, a dependência do país do transporte de longa distância. Mas, também, pelos ganhos em termos de segurança e defesa advindos da exclusão de potências rivais da área. Não obstante, desde 2012, a integração do MSC à órbita de poder chinês é considerada "de interesse nacional essencial"12 pelo PCC, o que poderíamos intitular como uma espécie de "espaço vital", seguindo o raciocínio de Ratzel.

\section{A geoestratégia chinesa para o MSC e o “Colar de Pérolas”}

Averiguados os valores econômicos e estratégicos do MSC, advindos de seu conteúdo e posição geográfica, além de sua importância para o Estado Chinês, é interessante verificar qual tem sido a geoestratégia da China para essa área. A estratégia militar de 2015, proposta pelo Presidente Xi Jinping, aponta para maior foco no fortalecimento do poder marítimo chinês para a proteção e defesa de seus direitos em detrimento da visão tradicional terrestre (CHINA, 2015). Ao mesmo tempo, Klare (2008) observa que diante do domínio marítimo anglo-saxão, especialmente em relação ao estreito de Malaca, os líderes chineses vêm mostrando preferência por rotas comerciais terrestres para o abastecimento de bens

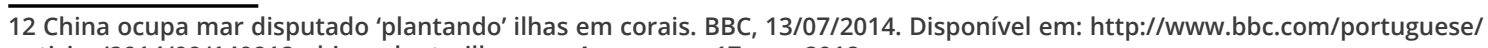
noticias/2014/09/140912_china_planta_ilhas_rm. Acesso em: 17 nov. 2018. 
estratégicos, especialmente os energéticos. Assim, a geoestratégia chinesa para o MSC, a partir de sua posição geográfica anfíbia no rimland, pode ser analisada tanto por ações relacionadas diretamente ao MSC, quanto às que buscam evitar ou driblar as restrições possíveis da passagem de Malaca. Isso significa que podemos olhar através de uma combinação da estratégia de expansão de poder marítimo no sentido de Mahan, para segurança de suas rotas marítimas estratégicas e de seu território, da busca pelo domínio territorial marítimo como fonte de recursos estratégicos no sentido de Ratzel, mas também pela expansão por via terrestre no sentido de Mackinder.

Blackwill \& Harris (2016) afirmam que, de forma geral, a estratégia chinesa para o MSC se guia a partir de três princípios: (i) impor custos elevados aos países que entrarem em disputas territoriais com Pequim; (ii) minar as alianças regionais dos EUA; e (iii) aumentar o círculo de amizades da China na região. Esses pontos vão se traduzir em projetos de infraestrutura ao longo do MSC, os quais em conjunto ficarão popularmente conhecidos como o "Colar de Pérolas" chinesas, conforme salienta Vázquez (2013, p. 128):

A expressão "colar de pérolas" foi utilizada pela primeira vez num documento interno do Departamento de Defesa da EUA intitulado "Energy futures in Asia" (o futuro energético da Ásia) [...] o Colar de Pérolas é um "cordão" de bases aéreas e navais, portos comerciais, "hubs" e corredores energéticos, centros de inteligência etc., mantidas pela China ao longo de suas principais rotas petroleiras, do mar Vermelho e do Golfo Pérsico até o Mar do Sul da China. Esta série de enclaves tende a rodear e estrangular quatro importantes penínsulas: a Indochina, a Indostânica, a Arábica e o Chifre da África. Como se havia adivinhado, esta disposição das fichas chinesas neste tabuleiro está em direta oposição à Índia... e, é claro, com a superpotência anglo-americana.

Para concretizar esses planos, Pequim tem utilizado de instrumentos econômicos com fins geopolíticos, o que Blackwill \& Harris 
(2016) denominam como geoeconomia. Essa ação é levada à frente por empresas estatais ("campeãs nacionais") e policy banks, com destaque para o recém-criado Banco Asiático de Investimentos em Infraestrutura (Asian Infrastructure Investment Bank - AllB).

Idealizado pela China em 2013 e aberto para negócios em 2016, o AllB nasce com 56 membros oficiais e hoje já conta com 87. Com um capital estimado de 100 bilhões de dólares, o objetivo desta nova instituição é investir em projetos de transporte, telecomunicações e energia ao longo da região da Ásia-Pacífico. Entre as iniciativas já aprovadas, pode-se citar a rodovia M-4 que deverá conectar de forma eficiente e segura as cidades de Islamabad, Faisalabad e Multan, garantindo a integração do espaço paquistanês e facilitando o trafego comercial vindo da Ásia Central para os portos de Gwadar e Karachi. Além disso, já foram emprestados US\$165 milhões para realizar o upgrade do sistema de distribuição elétrica de Bangladesh. Também foi aprovada a construção de um gasoduto conectando o centro produtor de Bakhrabad com a cidade portuária de Chittagong, logo elevando a capacidade de exportação desse país. Nas Filipinas, o projeto para modernizar a rede de águas e esgoto da região metropolitana de Manila recebeu aceite. E espera-se que com essa atualização sejam evitadas futuras enchentes durante a temporada de chuvas. Esses são apenas alguns dos projetos já aprovados e que interessam diretamente à China, pois se localizam em áreas onde o país pretende aumentar sua influência política e econômica. Simultaneamente, o AlIB representa para os Estados asiáticos uma alternativa de financiamento que não os tradicionais e intrusivos Banco Mundial e Fundo Monetário Internacional (FMI).

Rivalizando o alcance e as responsabilidades do Banco Mundial. Autoridades norte-americanas foram peculiarmente contundentes em sua avaliação, advertindo que o banco [AllB] é uma tentativa deliberada de minar as instituições financeiras internacionais estabelecidas após a Segunda Guerra Mundial (e dominada desde então pelos Estados Unidos, Europa e Japão). Além 
O Mar do Sul da China: seu valor estratégico e a geoestratégia chinesa

Raphael Padula • Felipe Gusmão Carioni Fernandes

de tentar enfraquecer o tecido da aliança dos EUA na região, o AllB poderia permitir que a China puxasse seus vizinhos para mais perto de sua órbita, em relacionamentos que prometessem maiores benefícios geoeconômicos, incluindo a diminuição da tensão sobre as reivindicações territoriais (BLACKWILL \& HARRIS, 2016, p. 115. Tradução nossa) $)^{13}$.

Outro instrumento de financiamento e investimento chinês que tem influência direta sobre a montagem do Colar de Pérolas é o Banco de Exportações e Importações da China (Export-Import Bank of China - Exim Bank). Tendo escopo similar ao AllB, o Exim Bank é, contudo, menos sutil em seu papel de agente da política geoeconômica do país. Isso fica claro a partir da descrição desse órgão em seu sítio eletrônico (tradução nossa) ${ }^{14}$ :

\begin{abstract}
O Banco de Importações e Exportações da China é um banco estatal com status de entidade legal independente. É um banco diretamente sob a liderança do Conselho de Estado e dedicado a apoiar o comércio exterior, o investimento e a cooperação econômica internacional da China. Com o apoio do credito do governo chinês, o banco desempenha um papel crucial na promoção do crescimento econômico estável e do ajuste estrutural, apoiando o comércio exterior e implementando a estratégia de "ida para fora". Compromete-se a reforçar o apoio financeiro a setores-chave e elos frágeis da economia chinesa para assegurar um desenvolvimento econômico e social sustentável e saudável [...] O principal mandato do Banco é facilitar as estratégias nacionais de desenvolvimento [...] Seu apoio financeiro vai para o comércio exterior, investimento
\end{abstract}

\footnotetext{
13 No original: Rivaling the reach and responsibilities of the World Bank. U.S. officials have been uncharacteristically blunt in their assessment, warning that the bank [AIIB] is a deliberate attempt to undercut the international financial institutions established after World War II (and dominated since by the United States, Europe, and Japan). Beyond attempting to weaken the U.S. alliance fabric of the region, the AllB could allow China to pull its neighbors closer into its orbit, into relationships that promise increased geoeconomic benefits including decreased tension over territorial claims.

14 No original: The Export-Import Bank of China is a state-funded and state-owned policy bank with the status of an independent legal entity. It is a bank directly under the leadership of the State Council and dedicated to supporting China's foreign trade, investment and international economic cooperation. With the Chinese government's credit support, the Bank plays a crucial role in promoting steady economic growth and structural adjustment, supporting foreign trade, and implementing the "going global" strategy. It is committed to reinforcing financial support to key sectors and weak links in the Chinese economy to ensure sustainable and healthy economic and social development (.-) The Bank's main mandate is to facilitate national development strategies (..) Its financial support goes to foreign trade, cross-border investment, the Belt and Road Initiative, international industrial capacity and equipment manufacturing cooperation, science and technology, cultural industry, "going global" endeavors of small and medium enterprises, and the building of an open economy.
} 
transfronteiriço, a Iniciativa Belt and Road, capacidade industrial internacional e cooperação na fabricação de equipamentos, ciência e tecnologia, indústria cultural, empreendimentos de pequenas e médias empresas relacionados a "ida para fora", e a construção de uma economia aberta (China, 2017).

Ao todo, é esperado que a China invista US\$ 62 bilhões em bancos estatais para apoiar as iniciativas de construção de infraestrutura ao longo do Sul e Sudeste Asiático e assim aumentar sua influência sobre a região (BLACKWILL \& HARRIS, 2016).

Agora, acerca dos projetos que constituem realmente as pérolas do colar chinês, (Figura 1), primeiramente, no âmbito do Oceano Índico, os que merecem destaque são: o oleoduto Myanmar-China; o porto de Gwadar no Paquistão; o porto de Chittagong em Bangladesh; a base militar chinesa em Djibuti e o porto de Hambantota no Sri Lanka. 
O Mar do Sul da China: seu valor estratégico e a geoestratégia chinesa Raphael Padula • Felipe Gusmão Carioni Fernandes

Figura 1 - Projetos do Colar de Pérolas da China

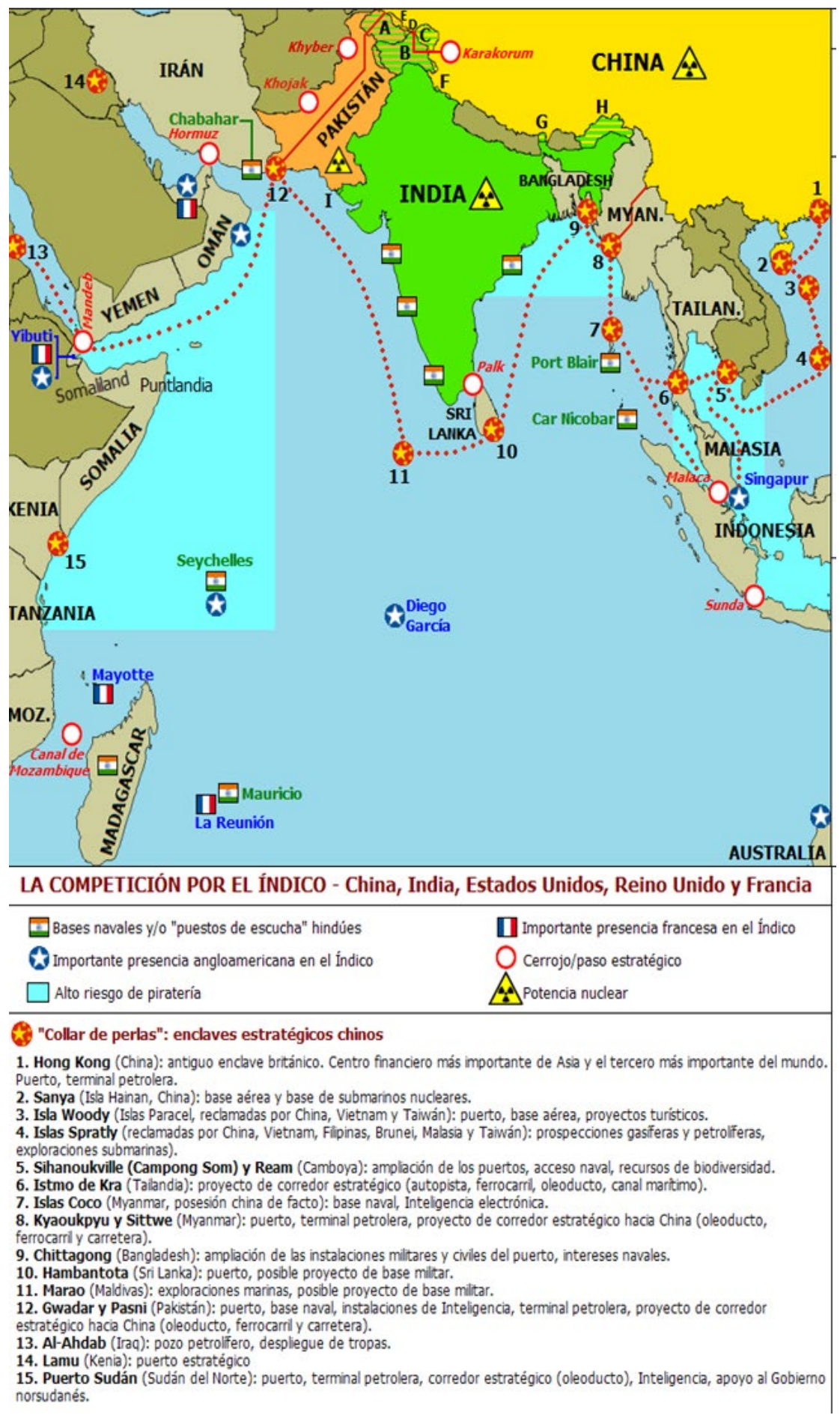

Fonte: Vázquez, 2013.

Orçado em 1,5 bilhão de dólares, construído e controlado pela petrolífera chinesa CNPC, o óleo-gasoduto Myanmar-China 
foi inaugurado em 2014. Esse óleo-gasoduto liga a cidade chinesa de Kunming ao Oceano Índico através do porto de Kyaukphyu em Myanmar. Tal infraestrutura permite aos cargueiros vindos do Oriente Médio que descarreguem no litoral do Índico e por meio do sistema de dutos transmitam até 22 milhões de toneladas de petróleo por ano (6\% aproximadamente das necessidades petrolíferas do país em 2016) até seu destino na China (KODAKA \& NITTA, 2017). Assim, economizando tempo e dinheiro e evitando a passagem desses recursos pelo Estreito de Malaca.

Os chineses estão construindo diversas instalações e dutos para receber petróleo e gás natural da África, do Golfo Pérsico e do Golfo de Bengala, e transportar estas mercadorias através do coração da Birmânia até a cidade chinesa de Kunming. Também se planeja para 2015 uma estrada e via férrea de alta velocidade [...] enquanto que, mais ao norte, na também [cidade] costeira de Sittwe os chineses mantêm um centro de inteligência e espionagem eletrônica (orientado especialmente, se supõe, ao tráfico marítimo) desde 1994, e também desenvolvem um porto e base naval (VÁZQUEZ, 2014, p. 148).

Da mesma forma, o porto de águas profundas de Gwadar, no Paquistão, reformado pela China ao preço de US\$123 milhões e operado pela estatal China Overseas Ports Holding Company, possibilita ao país maior capacidade de ação no estreito de Ormuz e no Golfo Pérsico. Ainda, esse projeto concede aos chineses uma saída ao Oceano Índico, uma vez que Gwadar se liga à cidade chinesa de Kashgar através da rodovia de Carácorum. Logo, criando um corredor econômico que articula o interior do território chinês com a costa paquistanesa. Estimativas do governo apontam que mais de um quarto do comércio da China poderá transitar através desse corredor quando ele estiver terminado (BLACKWILL \& HARRIS, 2016, p. 124). Além disso, esse projeto também aumenta a pressão para o alongamento da rede de óleo-gasodutos Irã-Paquistão até a China. Como assinala Escobar (2015): 
Empresas chinesas de construção já começaram a trabalhar na perna do gasoduto entre Nawabshah [cidade paquistanesa vizinha à Karachi] e o estratégico porto de Gwadar, próximo da fronteira do Irã. A China está financiando o trecho paquistanês do IP. E por razão muito séria: o IP, do qual o porto de Gwadar é entroncamento chave, é essencial num jogo de muito mais longo prazo: o corredor econômico China-Paquistão, de \$46 bilhões, que, completado, conectará Xinjiang ao Golfo Persa, pelo Paquistão.

Similarmente à Gwadar, o porto de Chittagong em Bangladesh, oferece uma parada segura à marinha mercante e de guerra chinesa no Oceano Índico. E se construído um corredor econômico, a exemplo do Paquistão, mais uma alternativa à passagem através do Estreito de Malaca terá sido criada. De acordo com Vázquez (2014, p. 164):

Chittagong é uma das cidades de crescimento mais rápido do mundo, além de porto de trânsito para 90\% das importaçõesexportações bangladeshianas e a saída natural para todo o sul da Ásia privada do acesso ao mar: Tibete, Butão, o Turquestão chinês, as Sete Províncias hindus, Nepal e algumas regiões da Birmânia ocidental. A China Harbour Company, em colaboração com as autoridades bangladeshianas, haviam investido em torno de 9 bilhões de dólares para transformar toda a costa sudeste do país e para desenvolver em Chittagong um porto de águas profundas, vários terminais comerciais para containers, uma ponte de 950 metros, um túnel subfluvial, um parque industrial e até uma estrada que conecta Chittagong a Kunming através da Birmânia. A natureza estratégica destes projetos permaneceu abundantemente clara quando o tenente coronel Moazzem Hossain, chefe de segurança da autoridade portuária de Chittagong, que havia estudado os portos de Le Havre (França) e Hamburgo (Alemanha), declarou sem mais nem menos que "Nossa intenção é substituir o porto de Cingapura". 
Em 2017, a China também inaugurou sua primeira base militar e naval em território estrangeiro. A mesma fica em Djibuti, Estado localizado no chifre da África e posicionado de frente para o estreito de Bab el-Mandeb e para Golfo de Áden. Segundo as autoridades chinesas, a base deve servir como um centro de logística para as tropas do EPL (Exército Popular de Libertação) mobilizadas no continente africano e para combater a pirataria presente naquela região do continente africano. Como aponta Fontdegloria (2017):

Essa instalação permitirá que a China ganhe presença em um enclave estratégico, pois o Djibuti faz fronteira com a Somália, a Etiópia e a Eritreia e fica entre o mar Vermelho e o golfo de Áden, uma das rotas marítimas e de abastecimento de energia mais importantes do planeta e essencial para o comércio chinês. O gigante asiático, além disso, já é o maior parceiro comercial do continente africano e investiu bilhões de dólares em infraestruturas, sendo que uma delas é a linha ferroviária que liga exatamente o Djibuti a Adis Abeba, capital da vizinha Etiópia.

Por fim, o porto de águas profundas de Hambantota tira proveito da posição central do Sri Lanka em relação ao Oceano Índico fazendo dessa infraestrutura um ponto de apoio estratégico para o tráfego do petróleo chinês do Golfo Pérsico. Esse projeto teve financiamento do Exim Bank e foi construído pelas companhias China Communications Construction Company e China Harbour Engineering Construction Company ao custo de US\$1,3 bilhão. Atualmente, a estatal China Merchants Ports Holdings é a maior acionista dentro da joint venture que controla aquela infraestrutura, possuindo $80 \%$ de suas ações. Além dos direitos de uso desta instalação por 99 anos (MUSHTAQ, 2017).

No que tange ao MSC, em específico, os principais projetos do Colar estão relacionados à construção de infraestrutura nas ilhas que pontilham esse espaço como: Hainan, Paracel, Spratlys e Scarborough. Ademais, existe o plano de integração do Sudeste Asiático com o território chinês através da ferrovia Pan-asiática, e os projetos relacionados ao Istmo de Kra. 
No MSC, a estratégia chinesa se pauta em expandir suas capacidades de negação de acesso a este espaço. Nesse sentido, a construção da base de submarinos de Yulin, localizada na ilha de Hainan, dá a Pequim capacidade de responder rapidamente a qualquer desenvolvimento no Mar do Sul. No que tange à infraestrutura dessa base, estima-se que ela seja capaz de abrigar simultaneamente 20 submarinos de diversos tamanhos, além de navios de superfície em seus portos. Suas cavernas, túneis de acesso e linhas de suprimento localizam-se debaixo de uma montanha feita de granito, o que contribui para a proteção das armas ali ancoradas. A base está dentro do raio de ação da força aérea chinesa, tendo sua defesa aérea assegurada. Contudo, Yulin também possui três torres de rádio e grande quantidade de prédios de escritórios, o que faz desse complexo militar forte candidato a se tornar o centro de comando e controle da frota chinesa do MSC. Portanto, a construção dessa base incrementa as capacidades de projeção regional da China, fortalecendo sua posição na disputa por rotas comerciais importantes e coagindo seus vizinhos a aceitarem sua Linha de Nove Traços15 (COOK, 2017). Sendo assim, os planos de construção de ilhas artificiais e expansão de outras formações presentes no MSC complementarão a estratégia chinesa de negação de acesso ao mar, encabeçada pelos projetos da base de Yulin. Devido à sua centralidade dentro desse espaço, os arquipélagos Paracel, Spratly e o recife de Scarborough são estratégicos para o controle do trânsito através do MSC. Logo, os principais investimentos chineses se darão no âmbito dessas três áreas.

No que concerne o arquipélago das Paracel, os esforços chineses têm sido traduzidos na construção de infraestrutura militar diversa ao longo da maior parte das ilhas que formam esse conjunto (AMTI, 2017a). O caso da ilha Woody é emblemático a este respeito. Essa é a maior e mais bem equipada formação das Paracel. Além da infraestrutura militar que inclui pista de pouso de 2,7 km, porto e abrigos para mísseis terra-ar, ela é a única que possui população civil permanente. O que Ihe concede uma ZEE.

15 Linha de Nove Traços corresponde ao espaço que a China demanda como de sua soberania dentro do MSC. A linha compreende toda a área das ilhas Paracels, Spratlys, e do recife de Scarborough, além de Taiwan. 
Portanto, esse parece ser o padrão que a China procurará reproduzir nas demais áreas que o país controla no MSC.

Quanto ao arquipélago Spratly, os investimentos chineses têm se concentrado em construir bases militares em três recifes específicos: Fiery Cross, Mischief e Subi. Todas essas bases possuem pista de pouso, hangares capazes de abrigar até 24 aeronaves de combate, portos, torres de rádio e radares, além de abrigos com teto retrateis para guardar mísseis terra-ar e galpões para o armazenamento de munição (AMTI, 2017b).

Por último, os projetos da China para o recife de Scarborough ainda se mantém apenas no papel. Os chineses detêm o controle de fato desta formação desde 2012, quando instalaram um navio na entrada de sua lagoa interna, impedindo que os pescadores filipinos acessassem a área (AMTI, 2017c). Contudo, dada a proximidade do recife com a ilha filipina de Luzon e o veredito da Corte Internacional de Justiça (emitido em 2016) acerca de sua soberania a respeito daquela formação ter sido favorável a Manila, Pequim tem demonstrado cautela em iniciar qualquer tipo de construção nessa área. Mesmo assim, recentemente, os chineses anunciaram que devem instalar uma estação de monitoramento ambiental no recife (JOCELYN, 2017).

A militarização das ilhas Paracel, Spratlys e do recife de Scarborough possibilita à força aérea e naval chinesa capacidade de operação sobre a quase totalidade do MSC. Os portos e pistas de pouso permitem o reabastecimento das armas sem a necessidade de retorno ao continente. Ainda, a presença de torres de rádio e radar aumentam o espectro da presença chinesa e sua capacidade de detecção sobre o MSC (demonstrado na Figura 2). Tudo isso resulta em ganhos de eficiência em missões de reconhecimento, vigilância, resgate, além de combate e defesa. Logo, o custo de oposição regional e internacional à China nesse espaço se torna cada vez mais elevado. 
O Mar do Sul da China: seu valor estratégico e a geoestratégia chinesa Raphael Padula • Felipe Gusmão Carioni Fernandes

Figura 2 - Atual Capacidade de Defesa e Detecção Chinesa sobre o MSC

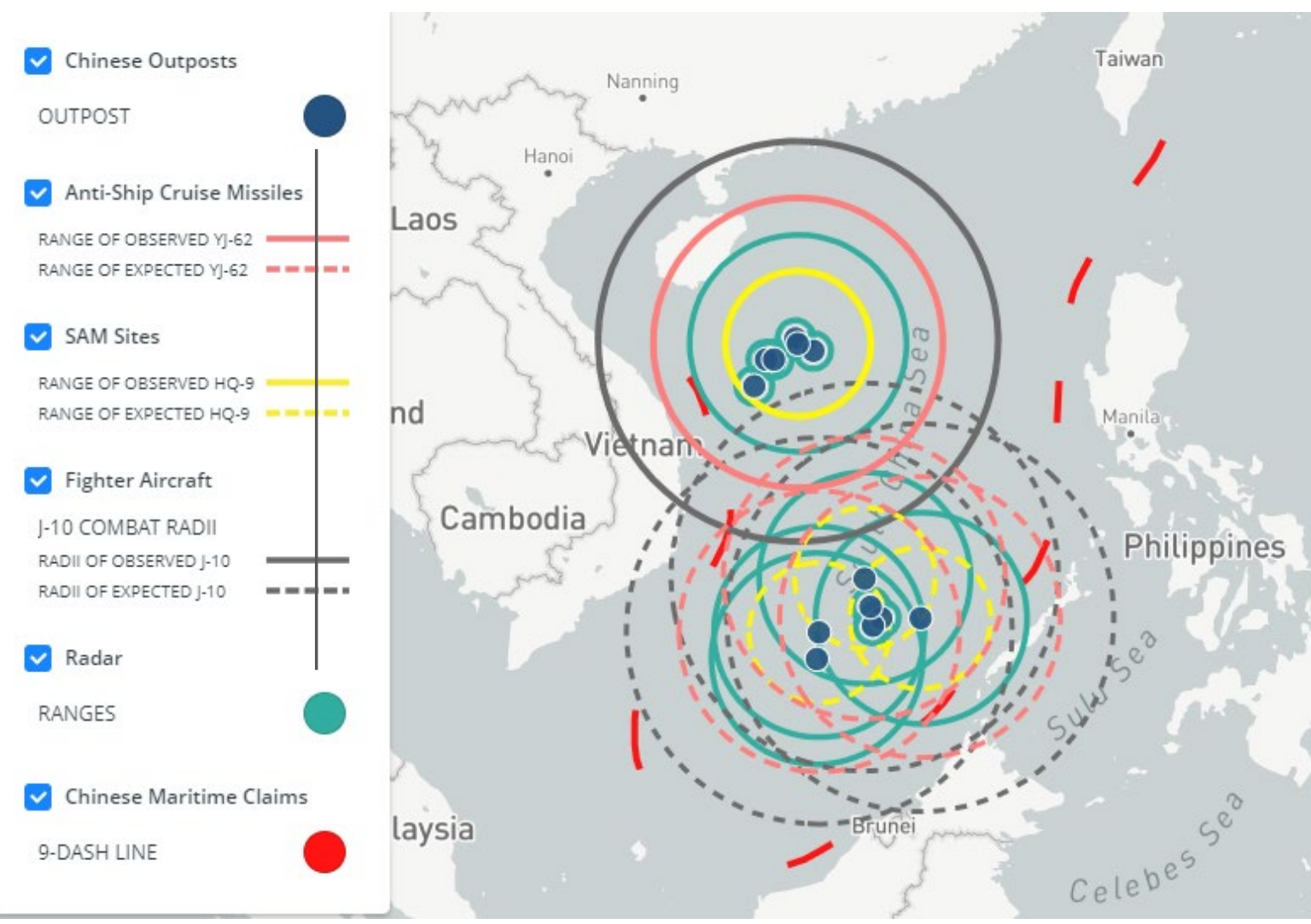

Fonte: AMTI, 2017.

Além das bases militares em ilhas, a concretização dos diversos projetos ferroviários que integrados formam a ferrovia pan-asiática podem ser percebidos como parte dos planos do Colar chinês, uma vez que esta infraestrutura permitiria evitar a passagem pelo estreito de Malaca, e aumentar o poder de atração econômica do país.

Portanto, a ferrovia pan-asiática16 divide-se em três rotas principais: oriental, central e ocidental. A primeira, quando estiver pronta, deve conectar a cidade chinesa de Kunming com Bangkok através do Vietnã e do Camboja. A rota central em sua extensão máxima conectará Kunming com Singapura, totalizando aproximadamente 4000 km que poderão ser percorridos em torno de 10

16 Pan-Asia Railway Network takes another step forward, 2016. Disponível em: http://www.railwaypro.com/wp/pan-asia-railway-network-takes-another-step-forward/. Acesso em: 26 nov. 2018. 
horas. Por último, a rota ocidental percorrerá o trecho de Kunming até Bangkok, mas dessa vez passando por Myanmar.

Entretanto, em caso de as investidas desestabilizadoras do atlantismo vingarem no Sudeste Asiático, de forma a impossibilitar a construção da ferrovia pan-asiática. A China poderá recorrer à construção de um canal bioceânico no Istmo de Kra (MELLOR, 2017). Ligando o Mar de Adamão, no Oceano Índico, com o golfo da Tailândia no MSC. Vázquez (2014, p. 143-144) resume a relevância desse empreendimento:

Isso deixa à China a opção de criar um novo estreito de Málaca, sob seu controle: escavando um canal no Istmo de Kra. A outra opção seria estabelecer portos, refinarias, terminais de gás natural, etc., de ambos os lados do istmo, e conectando estas instalações mediante um corredor comercial que incluiria um gasoduto, um oleoduto, uma via férrea e uma rodovia. O projeto do corredor teria $44 \mathrm{~km}$, uma largura de $500 \mathrm{~m}$ e dotado de rodovias, uma para cada sentido. Em suas diversas versões, o canal/corredor tailandês diminuiria, em relação a Málaca, entre 960-1300 km (de um a três dias) da rota entre o Índico e o Pacífico. E dependendo da profundidade, diminuiria entre 2.500$3.000 \mathrm{~km}$ (quatro a cinco dias) em relação ao estreito de Sunda, e de 3.000-3.500 km (cinco a sete dias) em relação ao estreito de Lombok. Os proponentes afirmam que um oleoduto cortaria os custos de transporte petroleiro na Ásia em 0.50 dólares por barril, e o gasoduto em 3 dólares por metro cúbico de gás. Assim, se converteria sem dúvida na pérola mais importante do colar chinês e numa "zona econômica especial" de importância global. A construção do canal levaria de cinco a sete anos, teria um custo de 20 a 25 bilhões de dólares.

Sendo assim, a ação de patrocínio de projetos de infraestrutura ao longo do Sul e Sudeste da Ásia e de expansão de bases militares no MSC parecem estar no centro da estratégia geoeconômica e geopolítica do país. Estas medidas têm potencial de modificar, não só a inserção regional, como também mundial da China através 
do domínio de espaços marítimos estratégicos uma vez que estes projetos estão relacionados diretamente à construção de poder regional do Estado chinês (statecraft). Logo, ao mesmo tempo, que proporcionam o acesso dos chineses a recursos naturais e estratégicos, também asseguram grande quantidade de capital político em favor deste país, na medida em que solucionam sérios gargalos nas redes de infraestrutura dos Estados próximos.

Sendo assim, a ação de patrocínio de projetos de infraestrutura ao longo do Sul e Sudeste da Ásia e de expansão de bases militares no MSC (Colar de Pérolas) parecem estar no centro da estratégia geoeconômica e geopolítica do país. E, fazendo referência a Mahan (1890), essas medidas têm potencial de modificar a inserção regional da China uma vez que a consolidação de um espaço de soberania marítima rico em recursos estratégicos e que possibilita o controle de rotas marítimas importantes, além de possibilitar a projeção do país para outras áreas passíveis de exploração inevitavelmente modificariam o já frágil equilíbrio de poder no Sudeste Asiático. Ainda, a garantia de boa vontade política em favor de Pequim (vide a solução de sérios gargalos nas redes de infraestruturas dos Estados próximos) facilitaria a penetração chinesa nessa região. Logo, como definia teoricamente Ratzel, a China lograria construir um espaço coeso e subordinado ao seu interesse nacional, por sua vez, facilitando sua expansão ao longo do continente basilar de Mackinder.

\section{Conclusões e Considerações Finais}

Devido à sua posição geográfica estratégica e aos recursos naturais presentes na região do MSC, principalmente petróleo, gás natural e pescado, esta é uma área de interesse estratégico ("essencial" ou "vital") para a China. Por essa razão, observou-se que a expansão chinesa ocorre de maneira orgânica nessa região, à medida que também cresce o orçamento de suas forças armadas. A China aprofunda seu controle através da construção de ilhas ar- 
tificiais e aparelhagem militar de demais formações naturais, utilizando ainda instrumentos econômicos com fins geopolíticos, mas também busca rotas para driblar possíveis restrições no estreito de Malaca. Dessa forma, aumentando seu espectro de vigilância e monitoramento da área. Consequentemente, elevando sua capacidade de negar o acesso ao espaço marítimo e assegurando, portanto, sua preponderância no longo prazo.

Ao mesmo tempo, a China vem se expandindo através do "Colar de Perolas", principalmente através de projeção geoeconômica. Ou seja, vem utilizando instrumentos econômicos como uma arma geopolítica em sua busca por rotas alternativas para driblar as possíveis restrições impostas por potências rivais, notadamente o domínio anglo-saxão, no estreito de Malaca. Portanto, parece combinar estratégias previstas em Ratzel, Mahan e Mackinder, de forma combinada, pois busca fortalecer seu domínio sobre recursos estratégicos, aumentar seu poder marítimo e domínio de uma rota marítima estratégica, e ao mesmo tempo interconexões terrestres importantes como alternativas.

Tal postura assertiva chinesa, aliada a rivalidades históricas e interesses de vizinhos na região, além da presença e interesse dos Estados Unidos, a maior potência global, na região, fomentam um quadro em que crescentes tensões e conflitos não devem cessar nos próximos anos, pelo contrário, devem ser acelerados, pois envolvem não só o equilíbrio ou a dinâmica de poder regional, mas também a disputa pelo poder global.

\section{Referências}

AMTI - Asia Maritime Transparency Initiative. China's continuing reclamation in the Paracel. 2017A.

AMTI - Asia Maritime Transparency Initiative. China's big three near comPLETION. 2017B. 
O Mar do Sul da China: seu valor estratégico e a geoestratégia chinesa Raphael Padula • Felipe Gusmão Carioni Fernandes

AMTI - Asia Maritime Transparency Initiative. Imagery suggests Philippine fishermen still not entering Scarborough Shoal. 2017c.

ASeAn \& China. Declaration on the Conduct of Parties in the South China Sea. Disponível em: htTps://asean.org/?Static_POST=DECLARATION-ON-THE-CONDUCT-OF-PARTIES-IN-THE-SOUTH-CHINA-SEA-2. 2002. ACESSO EM 22 NOV. 2018.

BeCKer, Bertha. Geopolítica da Amazônia. Estudos Avançados. São PAULO. v.19, N.53, P.71-86, 2005. ISSN 0103-4014. HTTP://DX.DOI. ORG/10.1590/S0103-40142005000100005.

BLACKWILL, Robert, HARRIS, JenNifer. War by other means: geoeconomics as a statecraft. New York, Council on Foreign Relations, 2016.

BP - British Petroleum Statistical Review. China's energy market in 2017. 2018.

BROZOSKI, Fernanda. A geopolítica contemporânea dos oceanos: A terRITORIALIZAÇÃo do ESPAÇO MARítIMO No SÉCULO XXI RIO DE JANEIRO, 2018. TESE (Doutorado em Economia Política Internacional - Universidade Federal do RIO DE JANEIRO, 2018.

China. Decreto do Presidente da República Popular da China n. 55 (Lel sobre águas territoriais e zonas adjacentes). Vigésima Quarta Sessão do Comité Permanente da Sétima Legislatura da Assembleia Popular Nacional, 1992. DISPONÍVEL EM: HTTPS://BO.IO.GOV.MO/BO/I/1999/01/LEINAC408.ASP. ACESSO EM: 22 NOV. 2018.

China, Ministry of National Defense. China's Military Strategy. Maio DE 2015. Disponível EM: HTTP://Eng.MOd.Gov.CN/Press/2015-05/26/conTENT_4586805.HTM. ACESSO EM: 23 ABR. 2019.

China poWer PROJECT. How much trade transits the South China SEA. 2017.

COSta, Wanderley. M. Geografia política e geopolítica. São Paulo, HUCITEC, 1992. 
O Mar do Sul da China: seu valor estratégico e a geoestratégia chinesa Raphael Padula • Felipe Gusmão Carioni Fernandes

COOK, Damen. China's Most Important South China Sea Military Base. The Diplomat, 09/032017. Disponível em: https://thediplomat. COM/2017/03/CHINAS-MOST-IMPORTANT-SOUTH-CHINA-SEA-MILITARY-BASE. ACESSO EM: 08 NOV. 2017.

ElA - Energy Information Administration. World Oil Transit Chokepoints. 2011.

ElA - South China Sea (Overview). 2013.

ESCOBAR, Pepe. Reshuffling Eurasia's energy deck - Iran, China and Pipelineistan. Asia Times [31/07/2015]. Disponível em: htTp://atimes. COM/2015/07/RESHUFFLING-EURASIAS-ENERGY-DECK-IRAN-CHINA-AND-PIPELINEISTAN-ESCOBAR/. ACESSO EM: 23 NOV. 2018.

FIORI, José.Luís., PADUlA, Raphael. “BrésiL: géopolitique et “ouverture sur Le Pacifique'"'. In: OutreTerre, L'Empire (Pacifique) Du Brésil. Paris, 2015.

Fernandes, Felipe G. C. Geopolítica e Geoeconomia do Mar do Sul da China: as disputas do gigante asiático pelo domínio de espaços marítlmos estratégicos. Dissertação (mestrado) - Universidade Federal do Rıo de Janeiro, Instituto de Economia, Programa de Pós-Graduação em Economia Política INTERNACIONAL, 2018.

FONTDEGLORIA, Xavier. China inaugura primeira base militar no exteRIOR. El PAís [02/08/2017]. DISPONÍVEL EM: HTTPS://BRASIL.ELPAIS.COM/BRASIL/2017/08/01/INTERNACIONAL/1501589492_007630.HTML. ACESSO EM 30 AGO. 2017.

haRVEY, David. A produção capitalista do espaço. São Paulo, AnNABLUme, 2005.

HOWELL, Sabina. Jia You! (Add Oil!): Chinese energy security strategy. In: Gal Luft and Anne Korin (Editors). Energy Security Challenges for $21^{\text {st }}$ Century: A Reference Handbook. Santa Barbara. ABC-CliO LlC, p. 191 $219,2009$. 
O Mar do Sul da China: seu valor estratégico e a geoestratégia chinesa Raphael Padula • Felipe Gusmão Carioni Fernandes

UY, Jocelyn R. China to build environmental monitoring station on Panatag. The Inquirer [18/03/2017]. Disponível em: https://globalnation. INQUIRER.NET/153472/CHINA-BUILD-ENVIRONMENTAL-MONITORING-STATION-PANATAG\#IXZZ5XgRJYVGG. AcESSO EM: 23 nov. 2018.

KAPLAN, Robert. A Vingança da Geografia: a construção do mundo geoPOLítico A PARTIR DA PERSPECTIVA GEOGRÁfICA. RIO DE JANEIRO, ELSEVIER, 2013. KAPLAN, Robert. Asia's Cauldron: the south china SeA and the end of stabe pacific. New York, Random House, 2014.

KLARE, Michael. Rising powers, Shrinking PLANet. NeW York, Metropolitan Books, 2008.

kODAKA, Wataru. \& NitTA, Yuichi. A new Myanmar oll pipeline helps China dodge US influence.

Nikkel Asia Review [20/04/2017]. Disponível em: https://ASIA.NIKKeI.COM/ MAGAZINE/20170420/Politics-ECONOMY/A-NEW-MYANMAR-OIL-PIPELINE-HELPSChina-dodge-US-influence. Acesso em: 07 nov. 2017.

LE BILLON, PhilipPe. The geopolitical ECONOMY OF RESOURCE WARS. IN: Philippe Le Billon, The Geopolitics of Resource Wars. New York, ROUTLEDGE, 2005.

LI, Zoe. China finds sign of oil near disputed Paracel Islands. CNN [16/07/2014]. DisPONÍVEL EM: HTTP://EDITION.CNN.COM/2014/07/16/WORLD/ ASIA/CHINA-PARACEL-ISLANDS-DRILLING-COMPLETED/. ACESSO EM: 15 OUT. 2017.

MACKINDER, Halford. John. (1904). “The Geographical

Pivot of History". The Geographic Journal, v. XXIII, N.4. April, 1904. DisPONÍVEL EM: HTTPS://WWW.IWP.EDU/DOCLIB/20131016_ MACKInderTheGEOGRAPHICALJOURNAL.PDF.

MAHAN, Alfred. Thayer. The influence of Sea power upon history 16601783. British Library, Historical Print Editions, 1890.

MEllo, Leonel Itaussu Almeida. Quem tem medo da geopolítica? São Paulo, Edusp, 2002. 
O Mar do Sul da China: seu valor estratégico e a geoestratégia chinesa Raphael Padula • Felipe Gusmão Carioni Fernandes

MEllor, William. Ambitious Thai canal would link Pacific and Indian oceans. NikKel Asia ReVIEW [10/08/2017]. Disponível eM: hTtPS://ASIA.NIKKEI. com/MAGAZINE/20170810/Politics-ECONOMY/AMBITIOUS-THAI-CANAL-WOULDLINK-PACIFIC-AND-INDIAN-OCEANS. ACESSO EM: 23 nov. 2018.

MOraes, Rodrigo. A Ascensão Naval Chinesa e as disputas Territoriais Marítımas no Leste Asıátıco. In: China em transformação: dimenSÕES ECONÔMICAS E GEOPOLÍTICAS DO DESENVOLVIMENTO / MARCOS ANTONIO Macedo Cintra, Edison Benedito da Silva Filho, Eduardo Costa Pinto (Organizadores) - RIO de JaneIRo, IPEA, 2015.

MUShTAQ, Munza. India and China flex muscles over SRi Lankan hub. Asia Nikkel Review [06/11/2017]. Disponível em: https://Asia.NikKel.com/ Politics-Economy/International-Relations/India-And-China-FLEX-MusCLESOVER-SRI-LANkAN-hub. Acesso em: 07 nov. 2017.

ONU - Organização das Nações Unidas (1982). Convenção das Nações UNIDAS SOBRE O Direito do Mar. DisPONÍVEL EM: HTTP://WWW.UN.ORG/DEPTS/ LOS/CONVENTION_AGREEMENTS/TEXTS/UNCLOS/UNCLOS_E.PDF. ACESSO EM: 24 NOV. 2018.

Pereira, Rui. A Questão do Mar do Sul da China no Contexto das Relações entre a China e os Países ASeAN. In: Nação e Defesa. Lisboa.

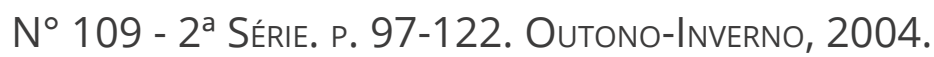

RATZEL, Friedrich. (1897). Géographie politique. Paris, Ed. Régionales EUROPÉNNES, 1988.

RATZEL, Friedrich. (1895). “Leis do crescimento espacial dos Estados”. Em Antonio Carlos Robert Moraes, Ratzel: Geografia. São Paulo, Ática, 1980.

Serrano, Carlos. A enigmática e rica região no Oceano Pacífico QUE PODE REDEFINIR O FUTURO DA MINERAÇÃO. BBC BRASIL [07/07/2018]. DisPoníVEL EM: HTTPS://WWW.BBC.COM/PORTUGUESE/GERAL-40520069. ACESSO EM: 23 NOV. 2018. 
O Mar do Sul da China: seu valor estratégico e a geoestratégia chinesa Raphael Padula • Felipe Gusmão Carioni Fernandes

Spykman, Nicholas. The Geography of the Peace. Yale, Harcourt, Brace and Company, 1944.

Storey, Ian., SChOfield, Clive. The South China Sea Dispute: Increasing Stakes and Rising Tensions. Washington D.C., Jamestown FOUDATION, 2009.

SUMAila, Rashid., CHEUNG, William. Boom or Bust: the future of FISH in the south china Sea. Hong Kong, ADM Capital Foudation, 2015.

VÁZQueZ, Daniel. A Rota da Seda, o Colar de Pérolas e a competıção pelo Índico (Parte 1/3). Tradução de Marcos Vinicius da Silva Dantas Fernandes. Revista de Geopolítica, Natal, v. 4, Nº 2, P. 127-154, JUl./dez. 2013.

VÁZQUeZ, Daniel. A Rota da Seda, o Colar de Pérolas e a competıção pelo Índico (Parte 2/3). Tradução de Marcos Vinicius da Silva Dantas Fernandes. Revista de Geopolítica, Natal, v. 4, Nº 2, p. 155-195, jUl./dez. 2013.

VÁZQueZ, Daniel. A Rota da Seda, o Colar de Pérolas e a competição pelo Índico (Parte 3/3). Tradução de Marcos Vinicius da Silva Dantas Fernandes. Revista de Geopolítica, Natal, v. 5, Nº 2, P. 129-180, jul./dez. 2014.

VilLar, Lejla., hamilton, Mason. The Strait of Malacca, a key OIL trade Chokepoint, links the Indian and Pacific Oceans. Energy Information Administration, 2017. Disponível EM htTPS://WWW.eiA.gov/TODAYINENERGY/DETAIL.PHP?ID=32452. ACESSO EM: 10 AGO. 2017. 